\title{
ABSENCE OF THE LEFT PULMONARY ARTERY IN FALLOT'S TETRALOGY
}

\author{
BY \\ RICHARD W. EMANUEL AND J. NORMAN PATTINSON \\ From the Departments of Cardiology and Radiodiagnosis, The Middlesex Hospital \\ Received July 28, 1955
}

Where the right or left branch of the pulmonary trunk (R.P.A. or L.P.A.) is absent, the main pulmonary vessel, after arising from the right ventricle, continues in an even curve to the hilum of one lung: there is no bifurcation of the main trunk and no pulmonary artery passing to the hilum of the other lung. Instances of this in association with Fallot's tetralogy have been reported. We are not considering here cases with absence or atresia of the main pulmonary trunk or absence of one pulmonary artery associated with complete agenesis of the ipsilateral lung.

Fraentzel (1868) was the first to describe a case of absence of the R.P.A. Four further cases were described during the next 73 years (Döring, 1914; Müller, 1927; Ambrus, 1936; and Miller, 1937). The first example of absent L.P.A. was recorded by Thomas (1941) in an infant with Fallot's tetralogy. The majority of cases with absence of either R.P.A. or L.P.A. have been reported in the last 8 years. Blalock (1947 and 1948) encountered 9 examples in his series of 610 cases of cyanotic congenital heart disease with pulmonary stenosis. Other cases have been reported by Campbell (1948), Bret and Feroldi (1950), Donzelot et al. (1952), Jew and Gross (1952), Madoff et al. (1952), Lowe (1953), Campbell (1954), Flynn et al. (1954), Madoff (1954), Read (1954), and Steiner (1954). Findlay and Maier (1951) and Steinberg et al. (1952) each described two examples. Three cases were recorded by Maier (1954) of which Case 3 had been previously reported by Findlay and Maier in 1951. A further 3 were described by Wyman (1954), 5 by Nadas et al. (1953) and 6 by McKim and Wiglesworth (1954).

The total number of cases recorded with absence of the L.P.A. or R.P.A. is 46 . In 6 of Blalock's (1947 and 1948) cases, however, it is not stated which branch of the pulmonary artery was missing, and in 2 of Wyman's (1954) examples, insufficient details of the cardiac abnormalities present were recorded for the purpose of this paper. Thus we are left with 38 cases for consideration. The patient of Sweet and White (1950) referred to by Findlay and Maier in 1951 has been quoted by some authors as an example of absent L.P.A., but has been omitted since there was a truncus arteriosus and no evidence of a pulmonary artery coming from the heart.

The observations in this paper followed the study of two cases of Fallot's tetralogy in which the L.P.A. was absent. There are reports of 18 similar cases; the L.P.A. was absent in 17 and the R.P.A. in the remaining case, but this was associated with dextrocardia and situs inversus (Nadas et al., 1953). In 10 of these 17 cases, the diagnosis was confirmed at necropsy. McKim and Wiglesworth (1954) reported a case of Eisenmenger's complex (confirmed at necropsy) in which the L.P.A. was missing. In these 21 cases, 19 previously reported and 2 reported here, the L.P.A. was absent in all, if it is assumed that absence of the R.P.A. with dextrocardia is embryologically equivalent to absence of the L.P.A. with lævocardia. The cardiac lesion common to all was a defect in the development of the bulbus cordis, giving rise to lesions of the upper part of the ventricular septum and infundibulum of the right ventricle. This appeared to be associated more frequently with absence of the L.P.A. than could be accounted for by chance. 
Nineteen reported cases in which absence of one or other branch of the pulmonary artery was associated with normal development of the bulbus cordis were collected for comparison. In 8 of these the heart was normal and in the remaining 11 ( 9 confirmed at necropsy) the lesion did not involve the bulbus cordis, the abnormality in the majority being confined to the great vessels (patent ductus arteriosus, 3 cases; coarctation of the aorta, 3 cases). In these 19 cases the R.P.A. was absent in 17, and the L.P.A. in the other 2. The frequency of absence of the R.P.A. in this group compared with that of the L.P.A. in the previous group suggested that there must be an embryological explanation for these findings.

The occurrence of right-sided aortic arch with Fallot's tetralogy has been recorded for over one hundred years (Corvisart, 1818), although it was not until 1936 that Bedford and Parkinson drew attention to the frequency of this association. More recently Taussig (1947) reported the incidence of right-sided aortic arch in these cases to be between $20-25$ per cent. In 20 cases of Fallot's tetralogy with absence of the L.P.A. (our 2 and 18 reported previously) we have found a much higher incidence of right-sided aortic arch for this occurred in 12 of the 20 cases $(60 \%)$.

The site of the aortic arch is stated in 16 of the 17 cases with absence of the R.P.A. In this group the heart was either normal or the lesion confined to the great vessels, but in no instance was a right-sided aortic arch recorded. This excludes the case of dextrocardia with Fallot's tetralogy mentioned above (Nadas et al., 1953).

\section{Discussion}

The standard embryological diagrams derived from Rathke, show both pulmonary arteries sharing equally the proximal parts of the sixth (pulmonary) arches. Bremer (1902 and 1909), however, whose studies include human embryos, disagreed with the conventional view and produced evidence that the original symmetry of these arches was disturbed by absorption of the proximal part of the left arch (A, Fig. 1) into the truncus pulmonalis. The adult plan is reached (Fig. 2) with the absorption of the distal part of the right sixth arch (B, Fig. 1), the corresponding part of the left sixth arch becoming the ligamentum arteriosum (C, Fig. 1). Keibel and Mall (1912) agreed with Bremer's work which received further support from Congdon (1922). Thus, it appears that the right and left pulmonary arteries differ embryologically. The right sixth arch forms the proximal part of the R.P.A. (D, Fig. 1 and 2) while on the left side the corresponding structure has been absorbed so that the L.P.A. contains no part of the left sixth arch.

Bremer's work makes it possible to account for our findings, which cannot be explained if the conventional view of symmetrical development of the two pulmonary arteries is accepted. In cases where the development of the bulbus cordis is abnormal, it appears that the absorption of the left sixth arch (A, Fig. 1) is affected and that this in a proportion of cases leads to absence of the L.P.A. In the other group where the bulbus cordis has developed normally, it is more difficult to explain why the R.P.A. is absent in such a high proportion of cases. It is possible, however, at the time when the left sixth arch is normally absorbed, that in some cases the proximal part of the right sixth arch (D, Fig. 1 and 2), is also involved in the absorption process, thus eliminating an essential part of the R.P.A. and preventing development of this vessel. Meanwhile the L.P.A. will develop normally. This accounts for all cases recorded except two, where absence of the L.P.A. was associated with a normal heart.

The practical significance of this is that absence of the L.P.A. is generally associated with Fallot's tetralogy, while absence of the R.P.A. is found either with normal hearts or those in which the congenital lesion is confined to the great vessels.

\section{CASE REPORTS}

Case 1. This girl, aged 6, was investigated at Middlesex Hospital in October, 1953. Cyanotic heart disease diagnosed at birth. Frequent squatting. Could walk only 50-100 yards at normal pace before dyspnœa forced her to stop.

Mentally normal. Moderate cyanosis and clubbing. Venous pressure normal. Pulse regular 90 a 
minute. B.P. $115 / 80 \mathrm{~mm}$. Hg. Heart enlarged. Cardiac impulse, right ventricular in character. Pulmonary systolic murmur, conducted to the right of the sternum, also heard over back but only on the right side. Second sound single.

Electrocardiogram, sinus rhythm, right ventricular hypertrophy of considerable degree (right axis deviation, vertical heart, tall $\mathrm{R}$ in V1, deep $\mathrm{S}$ in V6, T negative in V1 only). Hb. 127 per cent, $18.4 \mathrm{~g}$., P.C.V. 60.5 per cent. Chest X-ray, slight cardiac enlargement, left-sided aortic arch, pulmonary artery

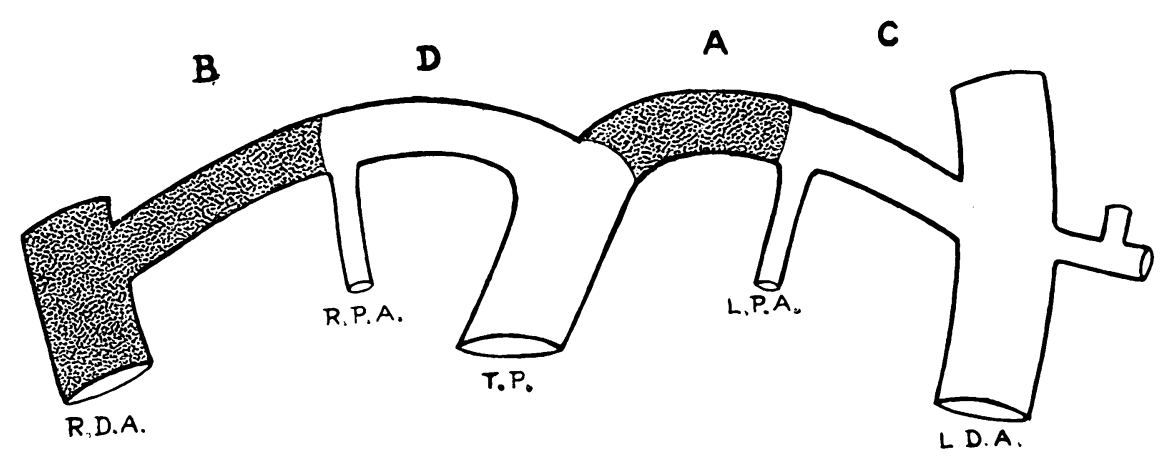

FIG. 1.-Diagram of the sixth (pulmonary) arch in the embryo. The shaded portions (A and B) are absorbed during development. A., Proximal portion of sixth (pulmonary) left arch. B., Distal portion of sixth (pulmonary) right arch and right descending aorta. C., Distal portion of sixth (pulmonary) left arch and left descending aorta. D., Proximal portion of sixth (pulmonary) right arch. R.D.A. and L.D.A., Right and left descending aorta. R.P.A. and L.P.A., Right and left pulmonary artery. T.P., Truncus pulmonalis.

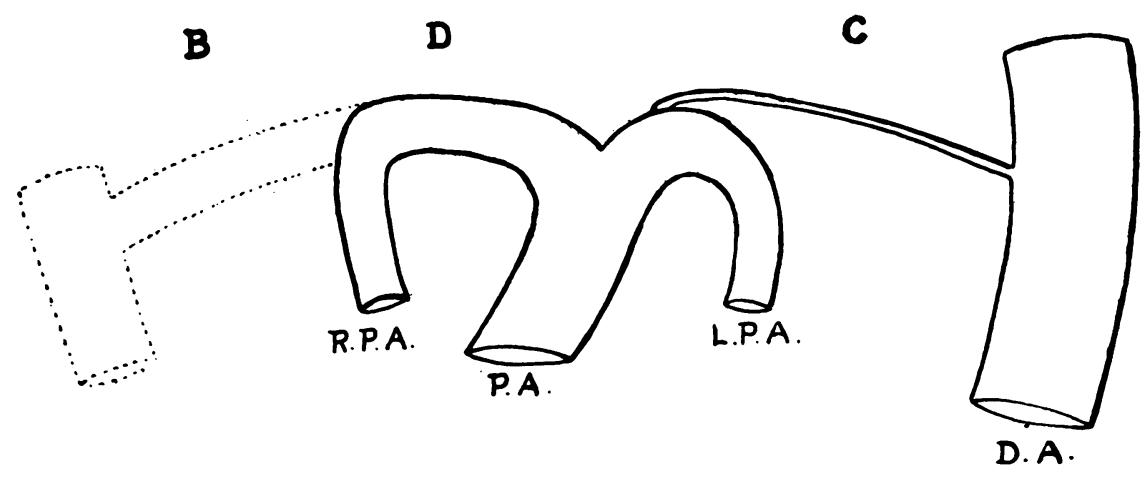

FIG. 2.-Adult pattern of the pulmonary arteries in man. P.A., Pulmonary artery. D.A., Descending aorta. For other letters see Fig. 1.

segment concave, and apex prominent and slightly elevated. Large R.P.A. and apparently small L.P.A. Angiocardiogram: large right ventricle, with simultaneous filling of aorta and small pulmonary trunk; stenosis of both pulmonary valve and infundibulum; R.P.A. very large and branches to the right upper and lower lobes almost aneurysmal. No trace was seen of the L.P.A.; there appeared to be a scanty bronchial arterial supply to the left lung, giving the appearances that simulated a small L.P.A. on the plain X-ray. The aortic arch was on the left and the vessels arising from it appeared normal (Fig. 3). Pulmonary veins were normal on the right, but none were seen on the left. Left atrium and left ventricle were outlined and the aorta was seen to refill with contrast medium. 


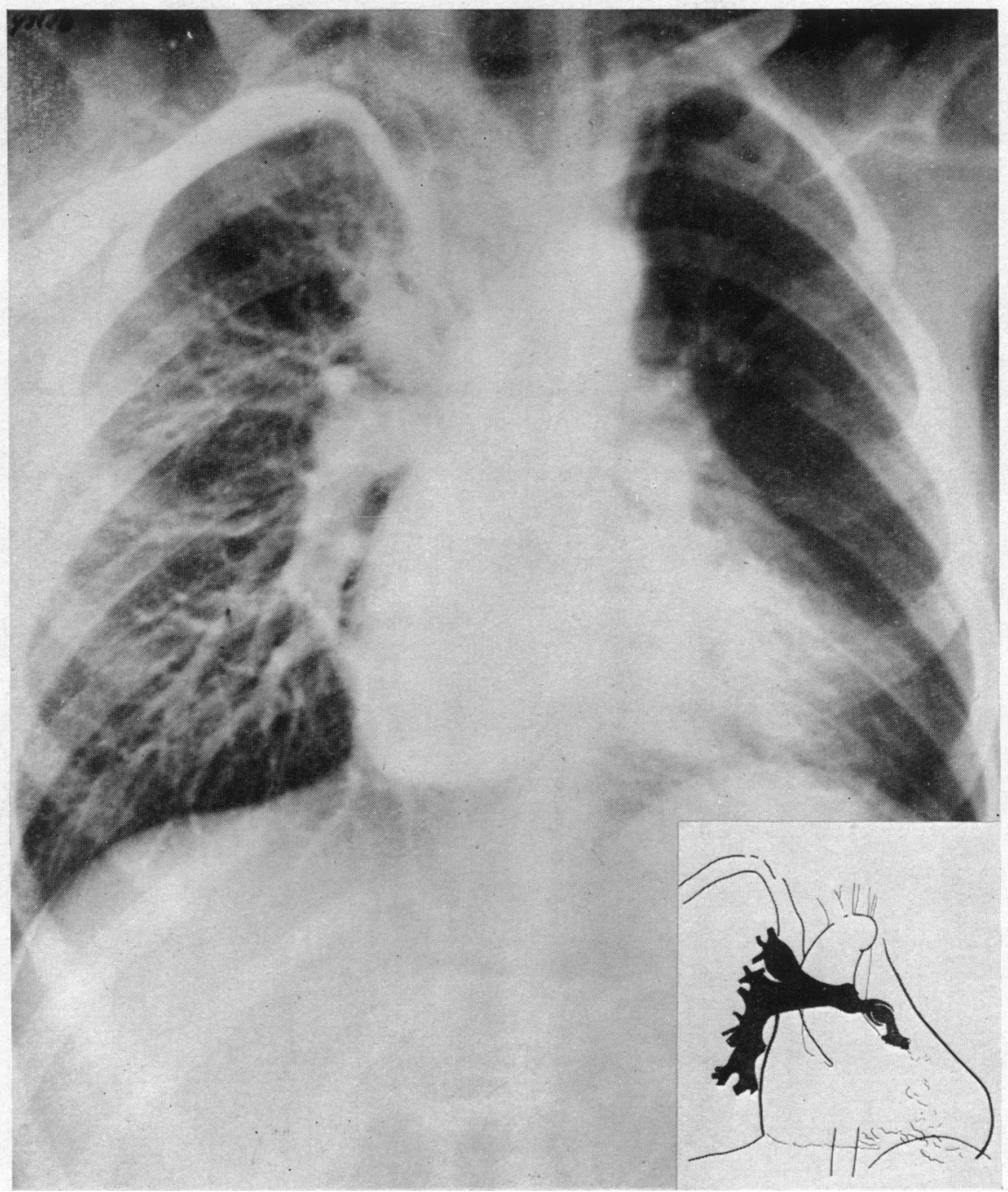

Fig. 3.-Angiocardiogram, showing absence of the left pulmonary artery associated with Fallot's tetralogy. Case 1.

Conclusion. Fallot's tetralogy with valvular and infundibular stenosis. Absence of left pulmonary artery with dilatation of the right pulmonary artery and major branches.

Case 2. This boy, aged 17 years, was investigated at Guy's Hospital and admitted to the Middlesex Hospital for operation in January, 1954. Cyanosed and clubbed since birth, with a history of frequent squatting until the age of 13 years. Severe effort intolerance, able to walk only a few yards before dyspnœa forced him to stop. Rheumatic fever when aged 9 and 11 years. Hæmoptyses when 13 years.

Mentally normal. Slight scoliosis and increased anteroposterior diameter of chest. Severe cyanosis and clubbing. Venous pressure normal. Marked arterial pulsation in neck. Pulse regular, 100 a minute, small volume. B.P. $125 / 85 \mathrm{~mm}$. Hg. Apex beat in anterior axillary line, not remarkable in character. First sound split at apex, second sound single at base followed by an immediate diastolic murmur which occupied the whole of diastole. No systolic murmur.

Electrocardiogram: sinus rhythm with right ventricular hypertrophy of moderate degree (right axis deviation, vertical heart, deep $\mathrm{S}$ waves V1-6, and T negative in V1 only). Hb. 160 per cent, $23.2 \mathrm{~g}$. P.C.V. 85 per cent. Chest X-ray: slight cardiac enlargement, with prominence of right ventricle; right-sided 
aortic arch, rib notching confined to right side, lungs oligæmic. Angiocardiogram (poor quality films): right-sided aortic arch filling from right ventricle; no main pulmonary artery seen, but both lung roots appeared to opacify, the right more so than the left; periphery of both lung fields equally filled. Cardiac catheterization: R.V. pressure of $96 / 2 \mathrm{~mm}$. $\mathrm{Hg}$ with a brachial artery pressure of $90 / 60$; oxygen saturation of blood from R.V. 56 per cent (4 samples) and from the brachial artery 65 per cent ( 2 samples).

This was considered to be a case of Fallot's tetralogy with rheumatic aortic incompetence. The site

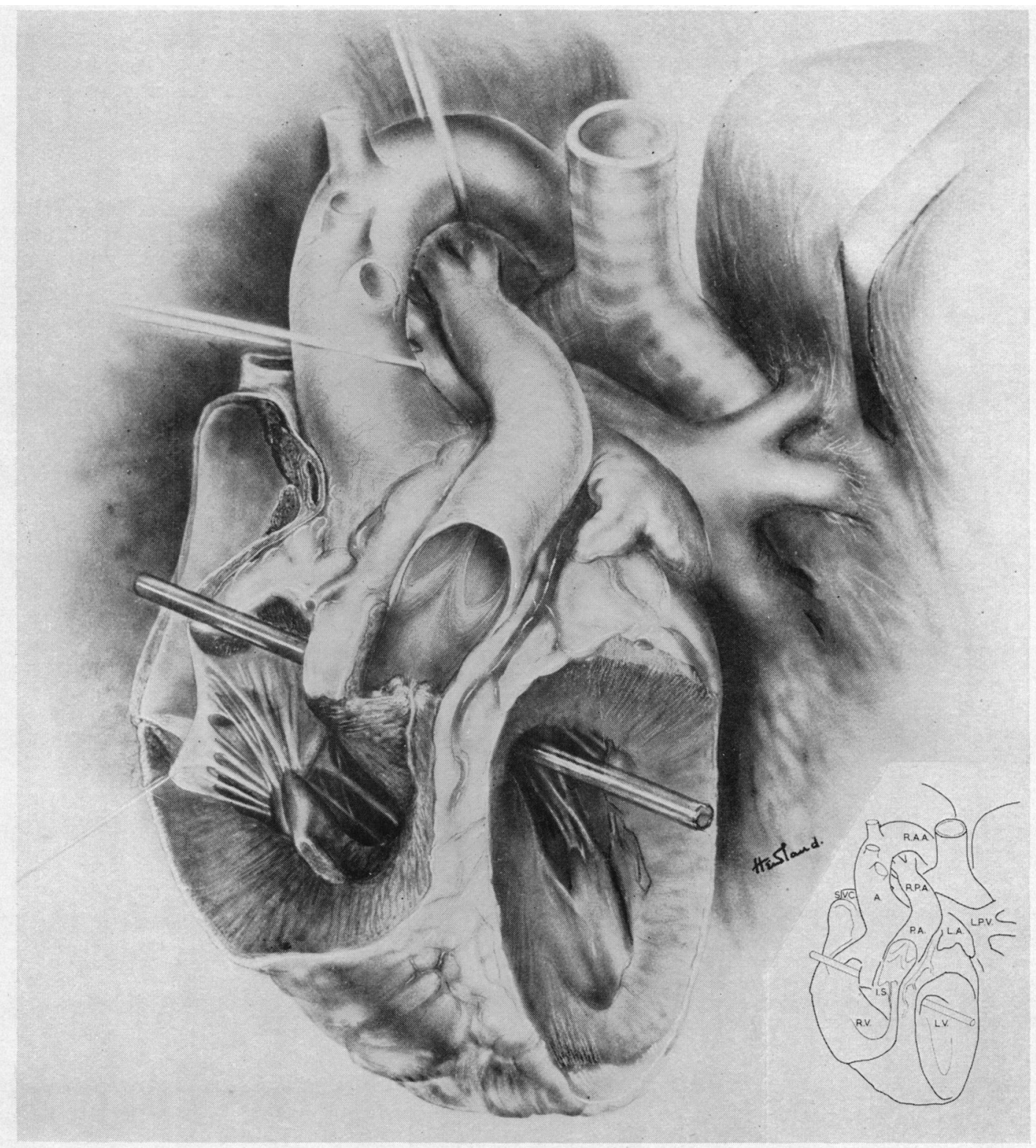

FIG. 4.-Drawing of necropsy specimen, showing absence of the left pulmonary artery associated with Fallot's tetralogy. Case 2. The rod is placed through the ventricular septal defect. S.V.C., Superior vena cava A., Aorta. R.A.A., Right aortic arch. P.A., Pulmonary artery. R.P.A., Right pulmonary artery. I.A., Left atrial appendix. L.P.V., Left pulmonary vein. R.V., Right ventricle. I.S., Infundibular stenosis. L.V. Left ventricle. 
of the pulmonary stenosis was not determined. Both right and left pulmonary arteries were thought to be present, though the left lung filled less than the right.

Operation. Many highly vascular adhesions between left lung and chest wall. Very large aorta and right ventricle. Small pulmonary artery and right main branch. No evidence of left pulmonary artery. Localized infundibular stenosis palpated. Death occurred five hours after attempts to enlarge the stenosed infundibulum.

Necropsy. The cause of death was bleeding from intercostal vessels and vascular adhesions. The presence of Fallot's tetralogy was confirmed. The L.P.A. was found to be completely absent. An infundibular pulmonary stenosis which was $1.7 \mathrm{~cm}$. in length admitted only a small probe. The cusps of the pulmonary valve were abnormal. The aortic cusps were thickened and thought to be incompetent, but there was no evidence of stenosis. The foramen ovale was not sealed. Both right and left ventricles were hypertrophied (Fig. 4).

\section{SUMMARY}

Two cases of Fallot's tetralogy are described in which the left pulmonary artery was absent.

We have collected a further 19 reported cases of congenital heart disease in which the development of the bulbus cordis was abnormal and was associated with absence of the left pulmonary artery. Of these, 18 occurred with Fallot's tetralogy. No case was found where abnormal development of the bulbus cordis was associated with absence of the right pulmonary artery.

In cases where the heart was normal or the cardiac anomaly did not involve the bulbus cordis, it was nearly always the right pulmonary artery that was absent (17 out of 19 cases).

In cases of Fallot's tetralogy associated with absence of the L.P.A. an unusually high incidence of right-sided aortic arch was observed-12 out of 20 cases or 60 per cent.

An embryological explanation is postulated to explain these findings: it supports Bremer's views on the development of the pulmonary arteries in man.

We are indebted to Dr. Evan Bedford for his help with the preparation of this paper and his permission to publish Case 1. We are grateful to both Dr. Maurice Campbell and Mr. T. Holmes Sellors for permission to publish Case 2. We received much help and guidance with the embryological aspects from Professor E. W. Walls.

\section{REFERENCES}

Ambrus, G. (1936). J. tech. Meth., 15, 103.

Bedford, D. E., and Parkinson, J. (1936). Brit. J. Radiol., 9, 776.

Blalock, A. (1947). J. thorac. Surg., 16, 244.

(1948). Surg. Gynec. Obstet., 87, 385.

Bremer, J. L. (1902). Amer. J. Anat., 1, 137.

- (1909). Anat. Rec., 3, 334.

Bret, J., and Feroldi, J. (1950). Arch. Mal. Coeur., 43, 714.

Campbell, J. A. (1954). Radiology, 62, 327.

Campbell, M. (1948). Guy's Hosp. Rep., 97, 1.

Congdon, E. D. (1922). Contributions to Embryology, No. 68 Carnegie Institute of Washington, $14,47$.

Corvisart, J. N. (1818). Essai sur les Maladies et les Lésions organiques du Coeur et des gros Vaisseaux. 3rd edit., Paris, p. 306.

Donzelot, E., D'Allaines, F., Dubost, C., Metianu, C., Durand, M., and Dubost, C. (1952). Sem. Hôp. Paris, $21,877$.

Döring, H. (1914). Stud. Path. Entw., $2,41$.

Findlay, C. W., and Maier, H. C. (1951). Surgery, 29, 604.

Flynn, J. E., Siebens, A. A., and Williams, S. F. (1954). Amer. J. med. Sci., 228, 673.

Fraentzel, O. (1868). Arch. Anat. Physiol. Lpz., 43, 420.

Jew, E. W., and Gross, P. (1952). Arch. Path., 53, 191.

Keibel, F., and Mall, F. P. (1912). Manual of Human Embryology. J. B. Lippincott and Co., Philadelphia and London, 2, 617 .

Lowe, J. B. (1953) Brit. Heart J., 15, 319.

Madoff, I. M. (1954). J. thorac. Surg., 28, 161.

-., Gaensler, E. A., and Strieder, J. W. (1952). New Engl. J. Med., 247, 149.

Maier, H. C. (1954). J. thorac. Surg., 28, 145.

McKim, J. S., and Wiglesworth, F. W. (1954). Amer. Heart J., 47, 845.

Miller, J. F. (1937). Amer. J. Dis. Child., 53, 1268.

Müller, L. (1927). Z. Kreislaufforsch., 19, 561. 
Nadas, A. S., Rosenbaum, H. D., Wittenborg, M. H., and Rudolph, A. M. (1953). Circulation, 8, 328.

Read, C. T. (1954). J. thorac. Surg., 28, 161.

Steinberg, I., Dotter, C. T., and Lukas, D. S. (1953). J. Amer. med. Ass., 152, 1216.

Steiner, R. E. (1954). Med. ill., 8, 577.

Sweet, R. H., and White, P. D. (1950). New Engl. J. Med., 242, 258.

Taussig, H. B. (1947). Congenital Malformations of the Heart. The Commonwealth Fund, New York.

Thomas, H. W. (1941). J. tech. Meth., 21, 58.

Wyman, S. M. (1954). Radiology, 62, 321. 